The outcome of replacing Sn completely by Ge in Kesterite Cu2ZnSnSe4 solar cells

Peer-reviewed author version

Sahayaraj, S.; BRAMMERTZ, Guy; VERMANG, Bart; Schnabel, T.; Ahlswede, E.; Huang, Z.; Ranjbar, S.; MEURIS, Marc; Vleugels, J. \& POORTMANS, Jef (2017) The outcome of replacing Sn completely by Ge in Kesterite Cu2ZnSnSe4 solar cells. In: 2017 IEEE 44TH PHOTOVOLTAIC SPECIALIST CONFERENCE (PVSC), IEEE,p. 3260-3264.

Handle: http://hdl.handle.net/1942/28576 


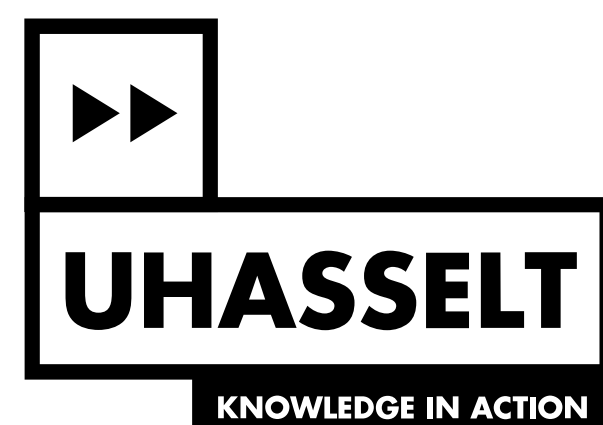

The outcome of replacing Sn completely by Ge in Kesterite Cu2ZnSnSe4 solar cells Link

Peer-reviewed author version

Made available by Hasselt University Library in Document Server@UHasselt

Reference (Published version):

Sahayaraj, S.; Brammertz, G.; Vermang, B.; Schnabel, T.; Ahlswede, E.; Huang, Z.; Ranjbar, S.; Meuris, M.; Vleugels, J. \& Poortmans, J.(2017) The outcome of replacing Sn completely by Ge in Kesterite Cu2ZnSnSe4 solar cells. In: 2017 IEEE 44TH PHOTOVOLTAIC SPECIALIST CONFERENCE (PVSC), IEEE,p. 3260-3264

DOI: -

Handle: http://hdl.handle.net/1942/28576 


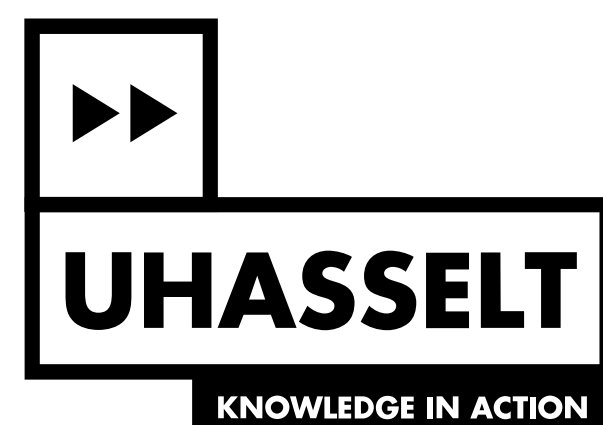

The outcome of replacing Sn completely by Ge in Kesterite Cu2ZnSnSe4 solar cells Link

Peer-reviewed author version

Made available by Hasselt University Library in Document Server@UHasselt

Reference (Published version):

Sahayaraj, S.; Brammertz, G.; Vermang, B.; Schnabel, T.; Ahlswede, E.; Huang, Z.; Ranjbar, S.; Meuris, M.; Vleugels, J. \& Poortmans, J.(2017) The outcome of replacing Sn completely by Ge in Kesterite Cu2ZnSnSe4 solar cells. In: 2017 IEEE 44TH PHOTOVOLTAIC SPECIALIST CONFERENCE (PVSC), IEEE,p. 3260-3264

DOI: -

Handle: http://hdl.handle.net/1942/28576 


\title{
The outcome of replacing Sn completely by Ge in Kesterite $\mathrm{Cu} 2 \mathrm{ZnSnSe} 4$ solar cells
}

S. Sahayaraj, G. Brammertz, B. Vermang, T. Schnabel, E. Ahlswede, Z. Huang, S. Ranjbar, M. Meuris, J. Vleugels, J.

Poortmans

\begin{abstract}
In this work, the fabrication and properties of a Ge-based Kesterite Cu2ZnGeSe4 solar cell have been discussed. The substitution and the existence of the quaternary compound has been verified by physical methods. The device has a power conversion efficiency of 5.5\% under AM1.5G illumination which is among the highest reported for pure Ge substitution. In depth electrical and optical analysis show that the $\mathrm{Cu} 2 \mathrm{ZnGeSe} 4$ absorber has less bulk defects, less or no band tailing and no sub band gap emissions, which are all characteristic of $\mathrm{Cu} 2 \mathrm{ZnSnSe} 4$ devices. These beneficial opto-electronic properties also result in a high open circuit voltage (Voc) of $744 \mathbf{~ m V}$ which is amongst the highest reported for Kesterite materials.
\end{abstract}

For the published version of record document, go to:

http://dx.doi.org/10.1109/PVSC.2017.8366159 
